\title{
Diversidade e educação de adultos: estratégias coletivas de resistências em tempos pandêmicos
}

\author{
Diversity and Adults Education: Collective Resistance Strategies in \\ Pandemic Times
}

\author{
Rayane Silva Guedes \\ Mestranda em Educação \\ Universidade do Estado de Minas Gerais - UEMG. \\ Belo Horizonte, Minas Gerais - Brasil. \\ rayanesguedes15@gmail.com \\ (iD) Daniela Oliveira Ramos dos Passos \\ Doutora em Sociologia \\ Universidade do Estado de Minas Gerais - UEMG. \\ Belo Horizonte, Minas Gerais - Brasil. \\ ddanipassos@gmail.com
}

Resumo: Este artigo tem como objetivo refletir sobre as possibilidades de educação de adultos, por meio da construção de estratégias coletivas de resistência à necropolítica (termo conceitualizado por Achille Mbembe, 2018), diante da marginalização de grupos de mulheres, negros, LGBTQIA+, indígenas, quilombolas, ocupações urbanas, população em situação de rua, entre outros, durante o período da pandemia. Para isso, utilizou-se como metodologia análise qualitativa e busca exploratória de coletividades atuantes nas mídias/redes sociais. Como resultado, foram encontradas 33 iniciativas de agências coletivas em Belo Horizonte e Região Metropolitana, mediante informações coletadas no aplicativo Instagram. Como considerações, entende-se que a perspectiva das redes sociais pode contribuir para os desenvolvimentos desses coletivos, como evidencia Fernanda Rocha (2017), fortalecendo os grupos e auxiliando a educação coletiva de adultos, na intenção de construir uma sociedade mais justa e equânime.

Palavras chave: diversidade; educação de adultos; necropolítica; pandemia.

Abstract: This article aims to discuss the possibilities of adult education through the development of collective resistance to necropolitics, (a term coined by Achille Mbembe, 2018), over the marginalization of groups of women, african american, LGBTQIA+, indigenous people, quilombolas, urban occupations, and homeless population, among other issues, during the pandemic period. This research was made, using a qualitative analysis methodology and the research of social media activism groups and communities. As a result, 33 collective initiatives were found in Belo Horizonte and the Metropolitan Area, using information collected from the Instagram app. Finally, we concluded that the social networks context can contribute to the development of these groups, as shown by Fernanda Rocha (2017), by consolidating groups and helping in a general adult education, aiming to build a more egalitarian and fairer society.

Key-words: diversity; adult Education; necropolitics; pandemic.

Cite como

(ABNT NBR 6023:2018)

GUEDES, Rayane Silva; PASSOS, Daniela Oliveira Ramos dos. Diversidade e Educação de Adultos: estratégias coletivas de resistências em tempos pandêmicos. Dialogia, São Paulo, n. 38, p. 1-14, e20434, maio/ago. 2021. Disponível em: https://doi.org/10.5585/38.2021.20434.

American Psychological Association (APA)

Guedes, R. S., \& Passos, D. O. R. (2021, maio/ago.). Diversidade e Educação de Adultos: estratégias coletivas de resistências em tempos pandêmicos. Dialogia, São Paulo, 38, p. 1-14, e20434. https://doi.org/10.5585/38.2021.20434. 


\section{Introdução}

Quando refletimos sobre o processo educativo, é comum que os sujeitos tenham compreensões diferentes a respeito do que é a educação, qual a sua função, ou mesmo a quem ela se destina. Ainda é lugar comum que as principais discussões, ou investimentos, girem em torno da educação de crianças, na concepção da educação como formação para a vida em sociedade (RODRIGUES, 2001). Além disso, é comum que as pessoas, ao expressarem suas intenções de construir um mundo melhor, depositem todas as expectativas na tenra idade como o "futuro da humanidade”. Não há dúvidas do potencial da educação de crianças e da necessidade de pensá-la e de transformar as suas práticas educativas. Entretanto, é preciso refletir sobre a urgência do avanço da construção de espaços de formação de adultos como possibilidade de progresso na elaboração de novas bases para uma sociedade mais equânime, como evidencia Paulo Freire (1989), principalmente diante do avanço de grupos de ódio, dos retrocessos nas políticas públicas, da propagação de fake news, do aumento da violência etc. Por isso, objetivou-se discutir, neste artigo, sobre a relação intrínseca entre o combate ao machismo, ao racismo, à violência praticada contra os LGBTQIA+, e a necessidade de uma educação de adultos que possibilite, como afirma Freire (1996), a transição entre o saber "ingênuo" e a criticidade.

Ouvir, reconhecer, pensar ou mesmo escrever sobre a educação de adultos nos exige assumir a existência de outros saberes e espaços de produção de conhecimentos que não são tradicionais. No atual contexto pandêmico ${ }^{1}$, esses saberem foram ainda mais necessários, pois as estratégias de sobrevivência de mulheres, negros, LGBTQIA+, trabalhadores, perante o alargamento das desigualdades, configuram-se como um rico saber, o qual precisa ser valorizado. No sentido de sua defesa, esses conhecimentos nos possibilitam avançar como sociedade, concebendo uma forma de resistir às situações extremas em que vivem esses coletivos. Entretanto, é importante que os saberes produzidos por meio da experiência sejam transformados em conhecimento crítico, de modo a possibilitar que se aglutinem saídas coletivas para o retrocesso em que o país se encontra.

Como metodologia, foram utilizadas a análise qualitativa da revisão de literatura, de tipo exploratória, e a análise documental, a partir do método comparativo constante (BOGDAN; BIKLEN, 1994), a fim de investigar organizações coletivas, de Belo Horizonte e Região Metropolitana, que têm contribuído para uma formação emancipatória de adultos, principalmente

\footnotetext{
1 A pandemia, aqui referida, iniciou-se no ano de 2019, a partir da propagação do novo Coronavírus, causador da doença Covid-19. Esse vírus possui alta taxa de transmissão e letalidade e pode ser transmitido por secreções contaminadas, por isso a medida de distanciamento social foi tão necessária para a tentativa de diminuição dos casos, como evidenciam Carvalho, Ninomiya e Shiomatsu (2020). Disponível em: https://coronavirus.saude.mg.gov.br/blog/108-distanciamento-social. Acesso em: 09 de jul. 2021.
} 
na atual situação de pandemia. Para isso, foi realizada uma coleta de informações na rede social Instagram $^{2}$, por meio das seguintes palavras-chave: movimento, luta, covid, corona, rede, coletivo, saúde, jurídico, periferia, grupo, movimento, mulheres, negros, indígenas, LGBTQIA+ e pandemia. Desse modo, foi possível selecionar 33 iniciativas coletivas, de acordo com os seguintes critérios: envolver mais de uma ou duas pessoas na elaboração da campanha, ter atividade explicitamente voltada para a pandemia e que antes não fosse realizada, e, ainda, estar com ações sendo desenvolvidas no momento da pesquisa. Então, a partir dessa coleta, foram analisadas as estratégias desenvolvidas pelos grupos selecionados, nomeadas, neste artigo, como: lives, atividades culturais e artísticas, financiamento coletivo, acesso à informação, parcerias, território nas redes e nas ruas e organização de trabalhadores em busca de emprego.

Para tanto, apresentam-se, ao longo deste artigo, experiências de organização coletiva que podem contribuir para pensar a educação de adultos, além de discussões sobre a questão da pandemia e os impactos que ela gerou para os diferentes grupos, no contexto da necessidade de contestação à necropolítica ${ }^{3}$ e à perspectiva neoliberal ${ }^{4}$. Em seguida, buscou-se relacionar o avanço e o desenvolvimento da quarta onda feminista, do movimento negro, do ciberativismo e de outras organizações como potencial para novas possibilidades de processos educativos de adultos, na tentativa de superação das desigualdades. Por fim, foram apresentadas as iniciativas de organização coletiva e redes de apoio durante a pandemia.

Com os desafios do tempo presente, faz-se necessário refletir sobre as práticas educativas que não necessariamente perpassam pela escola, mas que têm se mostrado como fruto de resistências de diferentes coletivos que contam, defendem e reescrevem sua história.

\section{Impactos sociais da pandemia}

É considerável que a pandemia, iniciada no Brasil em fevereiro de 2020, teve impactos diversos para a população (SANTOS, 2020). Alguns desses efeitos evidenciaram que nem todos/as/es vivenciam esse momento da mesma forma, e que as desigualdades se aprofundam diante das instabilidades econômica, social e de saúde, pois, ao invés de o país encaminhar-se para soluções promissoras, o que se observam são inúmeros projetos que colocam a nação na reta de novos retrocessos, mesmo após mais de um ano do início das infecções pelo novo Coronavírus.

\footnotetext{
2 Instagram é uma rede social, na qual as pessoas podem compartilhar vídeos e fotos. Disponível em :https://www.instagram.com/. Acesso em: 11 de jul. 2021.

3 Necropolítica, de acordo com Achille Mbembe (2018), é uma “política de morte”, na qual grupos de pessoas são colocados pelo Estado em situação de apenas sobreviver nas condições marginalizadas em que se encontram. Na contemporaneidade, há outros mecanismos de extermínio de sujeitos, criando outras formas de vivência social, garantindo, assim, a soberania do Estado.

4 Segundo Boaventura de Souza Santos (2020), o neoliberalismo é uma variante dominante do capitalismo, que está cada vez mais sujeito ao mercado financeiro global. Assim, todas as áreas, mesmo as sociais, como saúde e educação, estão à mercê do capital financeiro, a fim de gerar lucros. Isso levou o mundo a uma "crise humanitária” permanente.
} 
Por isso, para compreender as atuais condições às quais a população foi/está submetida é importante entender o motivo pelo qual tem se dado esses impactos na pandemia.

Sendo assim, faz-se pertinente conhecer a realidade do cenário nacional pandêmico, a fim de compreender quais estratégias tiveram que ser desenvolvidas para conter o avanço do vírus, para buscar a sobrevivência em meio ao cenário de crise que se instaurou, e quais os grupos sociais foram/são os mais afetados. Nesse sentido, em nota técnica ${ }^{5}$, o Núcleo de Operações e Inteligência em Saúde (NOIS) divulgou a informação de que o número de mortes de pessoas negras é superior ao de pessoas brancas: "Pessoas brancas e sem escolaridade têm uma proporção de óbitos de 47\% na enfermaria e $71 \%$ na UTI, enquanto negros e pardos, com a mesma escolaridade, têm 69\% e 87\%, respectivamente.” (2020, s.p.). Já para aqueles com ensino superior, “[...]a diferença é ainda maior: o percentual de óbitos de pretos e pardos é maior que o dobro do de brancos na enfermaria (16\% contra 7\%) e quase 60\% maior na UTI (64\% contra 40\%)." (2020, s.p.). Tais dados revelam evidências das desigualdades históricas a que o povo negro foi submetido e da urgência, ainda hoje, de políticas públicas que possam defender as suas vidas, em todas as frentes.

O aumento da violência doméstica também é um dado significativo a ser dito. Em janeiro de 2020, foram registradas 8.359 denúncias e 55.070 violações, somados os índices de "violência contra a mulher" e "violência doméstica e familiar contra a mulher", segundo dados da Ouvidoria Nacional de Direitos Humanos ${ }^{6}$ (Brasil, 2021). Já em maio de 2020, após o início da pandemia, o mês com maiores registros, foram 11.630 denúncias e 76.647 violações, um aumento significativo, considerando o fato de essas mulheres estarem confinadas em casa com os agressores, o que pode dificultar ainda mais a queixa. Contabilizando todo o ano de 2020, foram 105.672 denúncias e 519.368 violações referentes à violência contra a mulher. Já o total de registros - que compreende o Disque 180, o Disque 100 e os aplicativos da ouvidoria, independentemente do tipo de queixa foi de 349.851 denúncias e 1.416 .371 violações de direitos humanos, o que é reflexo direto do isolamento social e das crises econômica, social, política e sanitária vividos no país. Tudo isso demonstra que a questão da sobrevivência desses coletivos tornou-se ainda mais urgente, uma vez que houve um agravamento de condições sociais e de desigualdades que antes já se faziam presentes.

Vale ressaltar que a ideia de crise como um episódio esporádico pode ser contestada, diagnosticando-se que a pandemia aprofundou uma situação que já estava em andamento, inclusive se tornando justificativa permanente para a retirada de direitos, o que também ocorre nesse

\footnotetext{
5 Nota técnica 10 - 05/05/2020, Análise Socioeconômica da taxa de letalidade da COVID-19 no Brasil. Disponível em: https://sites.google.com/view/nois-pucrio/publica\%C3\%A7\%C3\%B5es>. Acesso em: 4 de jul. 2021.

6 Painel de dados da Ouvidoria Nacional de Direitos Humanos (ONDH). Disponível em: https://www.gov.br/mdh/ptbr/ondh/paineldedadosdaondh. Acesso em: 03 de jul. 2021.
} 
contexto pandêmico. Boaventura de Souza Santos (2020) reflete sobre como, desde 1980, parece que o mundo está em uma crise permanente, devido ao neoliberalismo. Tudo se justifica pela crise, mas não se buscam explicações para a origem dela e, dessa forma, ela serve para “[...] legitimar a escandalosa concentração de riqueza e boicotar medidas eficazes para impedir a iminente catástrofe ecológica. [...] Por isso, a pandemia vem apenas agravar uma situação de crise a que a população mundial tem vindo a ser sujeita.” (SANTOS, 2020, p. 6). Por causa dessa permanente recessão, a atual conjuntura é ainda mais "periculosa".

Além disso, o negacionismo contribuiu - e contribui - para o aprofundamento da crise sanitária e para o vilipêndio da urgência de adoção de políticas públicas que possibilitam o combate às opressões, bem como o enfrentamento ao desemprego. Assim, é possível delimitar que a fome também influencia o aumento da violência e marginaliza ainda mais um setor da população, em sua maioria negra, pobre e periférica. Como evidencia Boaventura Santos (2020, p. 19), "Deve salientar-se que para os moradores das periferias pobres do mundo, a actual emergência sanitária vem juntar-se a muitas outras emergências". Também, Ana Paula Morel (2021) afirma que, no Brasil, o negacionismo alcançou uma grande proporção, devido às declarações do presidente aos porta-vozes do governo, por vezes mascaradas de discurso científico com a participação de médicos ou empresas que possuíam diferentes interesses.

Outros pontos de destaque são o crescimento do conservadorismo, o avanço da extremadireita e a necropolítica. Essa "política de morte" se desenvolve, de acordo com Achille Mbembe (2018), na percepção de que, na contemporaneidade, de várias maneiras, são criadas populações de "mortos-vivos", pessoas que apenas sobrevivem, já que o Estado as condiciona a situações de sobrevida. Assim, "O que liga o terror, a morte e a liberdade é a noção "extática" da temporalidade e da política. [...] O presente em si é apenas um momento de visão - visão da liberdade que ainda não chegou" (Mbembe, 2018, p. 69-70), e a ideia de um Estado envolto em razão, democracia e liberdade é contraposto pela realidade de que a soberania é exercida por meio do poder de decidir quem vive e quem morre.

Dessa forma, na lógica do necroliberalismo, mulheres, negros e povos indígenas seriam vidas descartáveis. Nessa perspectiva, até mesmo os idosos foram vistos como um grupo que faria parte do "sacrifício", em detrimento da população "economicamente ativa". A própria defesa de ter o trabalho doméstico no grupo de atividades essenciais ${ }^{7}$ é exemplo de que algumas pessoas poderiam ser sacrificadas em favor de outras, pois “As mulheres são consideradas «as cuidadoras

\footnotetext{
7 O Decreto $\mathrm{N}^{\circ} 10.282$, de 20 de março de 2020, "Regulamenta a Lei nº 13.979, de 6 de fevereiro de 2020, para definir os serviços públicos e as atividades essenciais.” Disponível em: http://www.planalto.gov.br/ccivil_03/_ato2019-2022/2020/decreto/D10282.htm. Acesso em: 10 de jul. 2021.
} 
do mundo», dominam na prestação de cuidados dentro e fora das famílias." (SANTOS, 2020, p. 15). Cabe observar que esse grupo é essencialmente composto por mulheres e negras. Por isso, no período pandêmico, em que a necropolítica ganha força junto ao negacionismo, esses coletivos sofreram mais impactos, exigindo deles resistências e luta, principalmente no Sul do mundo, como confirma Boaventura Santos (2020).

Em suma, parte da ação desses grupos ocorre justamente pela ausência do Estado para assegurar as necessidades de uma parcela da população, além de sua incômoda presença em outros instantes. Assim, no momento em que um grupo se organiza para realizar uma "vaquinha" ou arrecadar alimentos, ele está cumprindo um papel do governo. Não somente isso, esses coletivos ainda desenvolvem cartilhas, campanhas de conscientização, dentre outras ações, bem como manifestam-se ao identificarem que o Estado atuou de forma excessivamente punitiva, por exemplo, quando um jovem negro é morto pelas mãos da polícia, cabendo, por conseguinte, a esses movimentos sociais discutir o problema do racismo institucional e exigir que os culpados sejam responsabilizados.

\section{Eduquemo-nos}

Há tempos, diferentes grupos têm se organizado na defesa de suas vidas, como a organização feminina que vem buscando melhorias nas condições de vida das mulheres. A primeira onda feminista, ainda no final do século XIX e no início do século XX, demonstrou a força das mulheres, principalmente quando elas desenvolveram ações e reflexões conjuntas (ROCHA, 2017). Angela Davis (2016) demonstra como a participação das mulheres nos movimentos abolicionistas contribuiu para uma organização própria em defesa de seus direitos, de forma que, na luta contra o racismo e a escravidão, elas puderam aprender e produzir saberes.

\footnotetext{
As mulheres desenvolveram habilidades de captação de recursos e aprenderam a distribuir publicações e a organizar encontros - algumas delas se tornaram poderosas oradoras. Mais importante de tudo, elas se tornaram eficientes no uso da petição, que se revelaria uma arma tática central na campanha pelos direitos das mulheres. Ao organizar petições contra a escravidão, foram compelidas a defender ao mesmo tempo o próprio direito de se envolver em ações políticas. (DAVIS, 2016, p. 58).
}

Isso não as eximiu de criar contradições e cisões, a exemplo das mulheres negras, as quais muitas vezes foram excluídas dessas primeiras organizações feministas, mas demonstra a potência que há na organização desses coletivos, como afirma Fernanda Rocha (2017). Em sequência, a segunda onda feminista, nas décadas de 1960 e 1970, possibilitou a reflexão sobre a característica social da opressão à mulher e abriu caminho para a reflexão da origem da opressão feminina. 
Entretanto, como forte demonstração de que os saberes construídos por esses coletivos e por seus sujeitos políticos também são históricos e se fazem na história, a terceira onda, nas décadas de 1980 e 1990, permitiu o avanço da crítica à exclusão das mulheres negras, pobres e do Sul do mundo na atuação política e social. Por isso, a efervescência desse período contou principalmente com a constituição de grupos de mulheres negras e do "terceiro mundo".

Atualmente, a quarta onda do movimento feminista tem demonstrado ser um forte contraponto à necropolítica, à medida em que defende a vida, de modo geral, junto ao movimento negro, aos LGBTQIA+, na defesa também do meio ambiente, dentre outras pautas. Essa nova onda se configura por intermédio dos espaços do ciberativismo, nos quais as mulheres se organizam em redes de apoio, segundo Fernanda Rocha (2017). A pesquisadora também aponta para a possibilidade de identificação, por meio das redes, quando as mulheres percebem em seus pares as mesmas questões opressivas. Dessa forma, os movimentos sociais favorecem a elaboração de novas perspectivas coletivas de libertação e de "luta política". Visando ao "bem-estar comum", esses grupos, na rede, têm mais oportunidades de transpor os limites geográficos de sua atuação e, até mesmo, os das pautas que defendem, pluralizando seus objetivos nas demandas que percebem em novas articulações (ROCHA, 2017). Entretanto, "rede e rua" se articulam, e as novas formas de organização na internet também refletem mudanças vindas dos espaços públicos das ruas. As manifestações, por exemplo, que aglomeram diferentes pautas também fazem avançar a conexão entre os coletivos, os sujeitos autônomos e as demais formas de estruturação, como sindicatos.

Nessa perspectiva, locais de encontro nas redes sociais, os quais possibilitam articulações diante do isolamento social, têm sido constituídos. Essas junturas foram/são manifestadas, a saber, pela divulgação de orientações sobre saúde e proteção contra o vírus e, também, de informações sobre como denunciar violências contra as mulheres, conseguir auxílios financeiros para as pessoas em situação econômica vulnerável, ou encontrar redes que apoiam pequenos produtores, comerciantes, trabalhadores locais etc.

Dessa forma, essas atividades desenvolvidas coletivamente produzem saberes, na medida em que os sujeitos nelas implicados se reconhecem enquanto coletivo e desenvolvem conhecimentos, técnicas e recursos para superar os desafios impostos. Especialmente nesse período de pandemia, esse contraponto é fundamental devido aos planos de austeridade e à ampliação das desigualdades, como explicitado. Paulo Freire (1996) já indicava que "Ninguém educa ninguém, ninguém educa a si mesmo, os homens se educam entre si, mediatizados pelo mundo". Por isso, é nas relações que se estabelecem na construção de coletivos e de grupos que a 
organização de mulheres, negros, LGBTQIA+, povos originários, pessoas com deficiência, entre outros, afirma a existência da possibilidade de novos espaços educativos.

Destarte, os coletivos e os movimentos sociais possibilitam, por meio de suas ações, que os indivíduos tenham experiências formadoras e transformadoras, no sentido da construção de um outro projeto de sociedade, pelo desenvolvimento de valores "éticos e humanitários", como evidencia Maria Gohn (2014). Assim, por meio das manifestações, ou mesmo da organização coletiva, são produzidos outros saberes. Dito isso, pode-se conceber que essas iniciativas fazem parte da educação de adultos, dentro da perspectiva dos espaços não formais:

\footnotetext{
Este debate, no campo dos estudos sobre os processos participativos civis, a exemplo dos movimentos sociais, traduz-se frequentemente no reconhecimento dessas ações coletivas como produtoras de conhecimento (ou seja, o reconhecimento de que os movimentos sociais, e outros atores sociais como ONGs, entidades do terceiro setor, são produtores e agenciadores de saberes). (GOHN, 2014, p. 35).
}

Para bell hooks (2013), as experiências do movimento negro e feminista, por exemplo, podem ajudar os sujeitos a avançar na percepção da realidade em que eles estão inseridos e a rumar para uma ação transformadora, emancipatória. Ela afirma, "Dentro dos movimentos feministas revolucionários, dentro das lutas revolucionárias pela libertação dos negros, temos de reivindicar continuamente a teoria como uma prática necessária dentro de uma estrutura holística de ativismo libertador" (p. 96). Sendo assim, com o movimento de ação-reflexão-ação, que Freire (1996) concebe, é possível que os movimentos construam espaços coletivos de formação de adultos, por meio da ação crítica da realidade em que estão inseridos.

Portanto, é fundamental reconhecer essas novas articulações como uma possibilidade de educação de adultos para conhecimentos muitas vezes depreciados, mas que se mostram fundamentais para pensar a formação de pessoas críticas e que se percebem dentro dessas identidades coletivas e se mobilizam em defesa de seus direitos, de suas vidas. Desse modo, a reflexão e a ação, aliadas, podem contribuir para a superação do negacionismo e a organização dos oprimidos contra a necropolítica, a partir do que pressupõe Freire:

\footnotetext{
Somente quando os oprimidos descobrem, nitidamente, o opressor, e se engajam na luta organizada por sua libertação, começam a crer em si mesmos, superando, assim, sua "convivência" com o regime opressor. Se esta descoberta não pode ser feita em nível puramente intelectual, mas da ação, o que nos parece fundamental é que esta não se cinja a mero ativismo, mas esteja associada a sério empenho de reflexão, para que seja práxis (FREIRE. 2002, p. 52).
}

Ainda, considerando-se essas experiências como formadoras, é importante refletir que esses saberes favorecem o desenvolvimento, mesmo que pessoal, daqueles que participam dos coletivos 
e dos que por eles são alcançados. Se, a partir das experiências, é cabível adquirir novas habilidades e novos conhecimentos, os quais poderão ser utilizados posteriormente, compreende-se a existência de uma experiência formadora, de acordo com Carmen Cavaco (2009). Apesar da tentativa de hegemonia e monopólio da escola sobre os processos educativos, naturalmente todos os sujeitos perpassam por espaços educativos, independentemente de onde ocorram (CAVACO, 2019). Então, essas experiências que possibilitam que os sujeitos adultos se eduquem em uma formação crítica contribuem também para motivar transformações sociais.

Nesse sentido, Nilma Lino Gomes (2017) reflete sobre como os saberes produzidos, especialmente pelo Movimento Negro, fazem parte das Epistemologias do Sul, por meio das ações por libertação analisadas no "[...] pensamento pedagógico como um permanente entre paradigmas de educação, de conhecimento, de valores e do humano" (2017, p.54), mediante uma hegemonia da valorização de pensamentos, valores e saberes do Norte do mundo. Afinal, todos os saberes importam, todas as histórias importam.

No próximo item, apresentaremos as principais iniciativas populares, em Belo Horizonte e Região Metropolitana, que contribuem para pensarmos uma sociedade mais justa e humana.

\section{Iniciativas populares e suas potencialidades}

As iniciativas apresentadas neste artigo não respondem à totalidade de movimentos, organizações, coletivos ou grupos, mas contribuem para refletir sobre a potência que eles possuem. Por isso, apresentaremos, nos subitens abaixo, as estratégias que espaços, em Belo Horizonte e Região Metropolitana, encontraram, no decorrer da pandemia, para planejar formas de intervenção e organização da resistência popular. Não se restringem a esse levantamento apenas grupos que surgiram durante a pandemia, mas buscamos abranger as organizações que antes já possuíam algum tipo de atuação e que foram significativas em suas ações.

$\mathrm{Na}$ compreensão da importância das redes sociais e virtuais para essas congruências e articulações, o levantamento ocorreu a partir de uma sondagem, nos espaços cibernéticos, para perceber as estratégias que foram utilizadas pelos coletivos, no período pandêmico, já que, como salientado, a internet possibilita diferentes articulações que antes não seriam possíveis. Por isso, essa busca ocorreu na plataforma Instagram, por meio das seguintes palavras-chave: movimento, luta, covid, corona, rede, coletivo, saúde, jurídico, periferia, grupo, movimento, mulheres, negros, indígenas, LGBTQIA+ e pandemia, na perspectiva que Bogdan e Biklen (1994) elucidam da possibilidade de a pesquisa qualitativa "descrever realidades múltiplas" (p. 73), por meio do levantamento de documentos em diferentes locais. Dessa forma, pelo "método comparativo 
constante", foi possível, ao longo da coleta, realizar ainda uma seleção de acordo com as categorias de análise às quais nomeiam os seguintes tópicos: lives, atividades culturais e artísticas, financiamento coletivo, acesso à informação, parcerias, território nas redes e nas ruas e organização de trabalhadores em busca de emprego. Ademais, levou-se em consideração para a coleta de dados a especificidade de ter atuado, de forma explícita, por motivo da pandemia, assim como, ainda no momento da pesquisa, desenvolver atividades. Ao todo foram selecionadas 33 iniciativas com diversas propostas, tanto para a garantia de alimentos quanto para a promoção de informação e cultura. Os critérios utilizados na seleção são os que mostraram, nos subitens, iniciativas desenvolvidas com atividades direcionadas à situação de pandemia e que de alguma maneira contribuíram para a promoção de um fazer político, coletivo e social para a vida, em seus múltiplos sentidos, como sinaliza Bogdan e Biklen (1994) para uma das possibilidades de análise na pesquisa qualitativa.

Tabela 1 - Lista de iniciativas

Nome dos coletivos

Objetivos descritos na Bio. ${ }^{8}$ \begin{tabular}{ll}
\hline Flores de Resistência e \#Fica "Uma campanha pela dignidade menstrual que atua na periferia de BH \\
em Casa & $\begin{array}{l}\text { conscientização e solidariedade \& resistência" }\end{array}$
\end{tabular}

Academia Transliterária e Campanha Cores e Sabores

Brejo das Sapas

Família Positiva BH

Unindo Forças BH

Meninas de Sinhá

Covida $\mathrm{BH}$

BH Sem Covid 19

Comitê Mineiro de Apoio à

Causa Indígena

Ribeirão em Defesa da Vida

Arebeldia
"Coletivo de Arte e Cultura Trans e Travesti em Minas Gerais."

"Esse espaço vêm para garantir a resistência do povo negro e LGBTQi+ que a muitos anos vive lutando por um lugar."

"Acolhemos pessoas que vivem e convivem com HIV/AIDS em MG. Informações e Acolhimento. Educação Comunitária do Estudo Mosaico/UFMG”

"Empresas, instituições e projetos sociais de BH unidos por um só propósito: colocar comida na mesa de quem precisa"

"Nosso objetivo é melhorar a vida da mulher idosa promovendo alegria, ação social, música, oficinas e geração de renda"

"Vidas sem fome durante a COVID-19"

"Coletivo de médicos(as), enfermeiras e profissionais da saúde trabalhando pela vida."

"Rede de indígenas em BH e RMBH, Minas Gerais, Brasil, Feminista, antirracista, antilgbtfóbico, decolonial."

"Juntas! Ações emergenciais para Defesa da Vida e da Saúde nos territórios de Ribeirão das Neves."

“Associação Cultural Arebeldia. Alto Vera Cruz/ BH"

\footnotetext{
${ }^{8}$ Bio é a biografia de cada perfil no aplicativo Instagram, onde as pessoas podem inserir informações referentes aos objetivos de cada projeto.
} 
Nome dos coletivos

Espaço Raízes BH

Serrão sem Corona

Corona na Quebrada

Comida que abraça

Linhas do Horizonte

Lá da Favelinha

Movimento Autônomo T BH

Direito das Minas

Centro de Estudos Pesquisa e Intervenção - Ribeirão das Neves (CEPI Neves)

Desencarceramg

Mães pela Liberdade - MG

Solidariart

Professores na Pandemia

Canto da Rua Emergencial

Periferia Viva

Eu amo minha quebrada

Centro Cultural Di Quebrada

Mulheres da Quebrada

Coletivo bELAS
Objetivos descritos na Bio. ${ }^{8}$

"Vamos juntar forças pra combater a Covid 19."

"Frente de ação do Aglomerado da Serra para salvar a favela do \#coronavírus."

“Informação de responsa e ações de apoio pra quebrada."

"Projeto que transforma comida em dignidade e esperança para a população em situação de rua."

“O Linhas do Horizonte é um coletivo de Belo Horizonte, fundado em 2016, suprapartidário de esquerda que se expressa através do bordado."

"Centro cultural independente, auto gerido pelos moradores do aglomerado da serra/Bh"

"Ação social, caminhada pelas vidas,

acolhimento, cidadania."

"Ajudamos mulheres a conhecerem os seus direitos"

“Centro de Estudos Pesquisa e Intervenção - Ribeirão das Neves. Na luta por \#terra \#comida \#trabalho e \#alegria."

Frente Estadual pelo Desencarceramento- MG

"Este coletivo promove ações em apoio às famílias das comunidades LGBTQIA+ no Estado de Minas Gerais."

Iniciativa de troca de obras artísticas em cestas básicas para contribuir com duas ocupações. ${ }^{\text {? }}$

"Diálogos em defesa da Educação na Pandemia"

“Conexão e convergência de saberes na promoção e defesa de direitos da população em situação de rua.”

"Rede que reúne iniciativas sociais de BH e Minas. Promovemos a vida onde ela está mais ameaçada pela pandemia: nas periferias."

"Projeto de Impacto Social no Morro do Papagaio"

Iniciativas de promoção da cidadania. ${ }^{10}$

“[...] promover em questões que envolvam o ser mulher um cuidado mútuo por meio da integração sociocultural, do fortalecimento de vínculos e da valorização feminina do Aglomerado da Serra, BH." "11

"Pensando e realizando ações de fortalecimento a autoestima de mulheres em situação de vulnerabilidade social em BH e Região."

\footnotetext{
9 Como essa iniciativa não possui biografia, as informações foram encontradas em um post disponível em: https://www.instagram.com/p/COWSEFQhqcR/. Acesso em: 11 de jul. 2021.

10 Informação disponível em:<https://www.instagram.com/stories/highlights/17870870566980279/>. Acesso em: 12 de jul. 2021.

11 Informação disponível em: <https://www.instagram.com/p/B2P9jOtBKfT/>. Acesso em: 12 de jul. 2021.
} 


\begin{tabular}{ll}
\hline \multicolumn{1}{c}{ Nome dos coletivos } & \multicolumn{1}{c}{ Objetivos descritos na Bio. $^{8}$} \\
\hline Coletivo Tereza de Benguela & $\begin{array}{l}\text { "Serviços: Faxina empresarial,domiciliar, eventos, passadoria e lavanderia. } \\
\text { Objetivos: Capacitação, direcionamento,valorização e emancipação." }\end{array}$ \\
"Coletivo autônomo formado por pessoas LGBT+ e colaboradorxs cis-hetero de \\
Bede P.O.C. & BH e região." \\
"Uma iniciativa sócio-cultural que promove cidadania através da cultura e da \\
Coletivo Balaio & promoção de direitos em Justinópolis, Ribeirão das Neves." \\
\hline
\end{tabular}

Fonte: Produzida pelas autoras, por meio da busca dos perfis do Instagram listados.

\subsection{Lives}

As lives $^{12}$, durante esse período de isolamento social, mostraram-se uma importante ferramenta de engajamento, discussão de pautas e difusão de atividades culturais. Além disso, como elas ficam gravadas, a sua produção constitui posteriormente um material informativo, já que, mesmo que uma pessoa não tenha acesso síncrono à atividade, ela pode acessar e compartilhar o conteúdo.

Os temas desses encontros virtuais foram diversos: dignidade menstrual, empoderamento materno, movimento LGBTQIA+, grafite, autocuidado, videoaulas de música, arte, alimentação, mulheres no funk, empregabilidade trans e métodos contraceptivos. Também, foram tratados assuntos como aborto, violência obstétrica, saúde sexual da mulher lésbica, sistema penal, luta anticárcere, denúncia de torturas nos presídios, vacinas, mulheres no samba e na poesia, autoestima das mulheres em situação de vulnerabilidade, dentre outras questões.

Similarmente, foram produzidos vídeos de apoio às campanhas, que contavam com a participação de artistas e figuras públicas em defesa das pautas. Esses vídeos, menores que as lives, também serviram para apresentar os organizadores e a comunidade atingida.

É importante sinalizar que também ocorreram atividades em outras plataformas, além do Instagram. Entretanto, a recorrência dessa ferramenta demonstra a possibilidade de compartilhamento entre os coletivos e a articulação com outros grupos, já que muitas vezes a live e os vídeos produzidos contavam com a presença de participantes que não eram da organização, mas que estabeleciam parcerias. Nessa conjuntura, é perceptível a troca de saberes, mas também de afetos.

\footnotetext{
12 Live é a expressão que se refere a um tipo de vídeo produzido, quando ocorrido pelo Instagram. Essa ferramenta permite uma hora de gravação. Nem todos podem falar abertamente nesse formato, mas o apresentador pode "convidar" pessoas a falar durante a atividade. Esses vídeos ficam registrados na plataforma IGTV, integrada à rede.
} 


\subsection{Atividades culturais e artísticas}

Nas plataformas dos coletivos selecionados, podemos visualizar iniciativas de cunho artístico e cultural realizadas por intermédio de saraus online, oficinas de música, lives com artistas, dançarinos, entre outros, que objetivaram promover o acesso a essas atividades, na perspectiva do fazer artístico como direito. Tudo isso, buscando apoiar artistas periféricos, em especial aqueles que faziam seus trabalhos nas ruas ou nos espaços culturais da cidade e que, com o distanciamento social, ficaram sem renda, ou, ainda, na compreensão da necessidade de manter o acesso à arte, inclusive como forma de manutenção da vida, e possivelmente ampliá-lo. Exemplo disso foram as oficinas de canto, bordado, violão, yoga, pilates, vogue e funk, ministradas pelo "Centro Cultural Lá da Favelinha”, com a intenção de promover arte e cultura no Aglomerado da Serra. Essas atividades foram desenvolvidas pelo canal do grupo no Youtube ${ }^{13}$.

Semelhantemente, o "Coletivo Balaio" produziu o sarau Balaiada: até no lixão nasce flor, a fim de divulgar e apoiar artistas de Ribeirão das Neves. Para isso, nos dias de evento, participaram uma dançarina, um ator circense, um arte educador produzindo pixos, além de uma técnica de arte circense e dançarina, dois dançarinos de passinho, uma educadora circense e dois Freestyle. Essas apresentações contribuíram para divulgar o trabalho dos artistas e para promover arte e cultura nas redes. Uma vez que os artistas da região muitas vezes não encontram espaço para divulgar o seu trabalho, eles puderam, com essa iniciativa, ganhar mais visibilidade.

Podemos perceber, portanto, que tais ações possibilitaram uma ampliação do acesso a produções culturais. Vale ressaltar que, mesmo antes da pandemia, ir a teatro, show, musical ou apresentação artística poderia ser inacessível a um setor da população. Entretanto, é preciso reconhecer que a própria democratização do acesso à internet ainda é uma questão que, apesar de ter avançado, precisa ser discutida, pois, infelizmente, não é realidade em todo o país.

\subsection{Financiamento coletivo}

Os financiamentos coletivos, ou "vaquinhas", podem demonstrar uma administração coletiva de renda colaborativa. Sobre isso, cabe destacar que os principais canais de arrecadação foram as ferramentas PIX ${ }^{14}$, Evoé ${ }^{15}$, PicPay $^{16}$, conta dos organizadores, além dos pontos de apoio físicos para que fosse possível receber alimentos, roupas, kits de higiene pessoal, doações etc. Com os financiamentos coletivos, observamos que os grupos se preocuparam com a transparência em

\footnotetext{
13 Youtube é uma plataforma de compartilhamento de vídeos.

14 PIX é uma forma de pagamento eletrônico, lançada em outubro de 2020, que usuários de qualquer banco nacional podem acessar de forma rápida.

${ }^{15}$ Evoé é uma plataforma digital de financiamento coletivo que recebe projetos, inclusive vinculados à Lei de Incentivo à Cultura.

${ }^{16}$ PicPay é um aplicativo que funciona como uma carteira digital. Nele, pode-se pagar contas, fazer compras ou realizar transferências.
} 
relação ao uso do valor arrecadado, demonstrando-a a partir de lives de prestação de conta ${ }^{17}$, ou mesmo de fotografias das entregas de alimentos, roupas, itens de higiene pessoal etc. Essa questão se mostra fundamental, principalmente para que aqueles que contribuíram possam ter um retorno quanto à legitimidade das ações desenvolvidas pelos projetos e se sintam motivados a continuar contribuindo.

Cada iniciativa, ou "vaquinha", tinha uma motivação específica, podendo ser, até mesmo, a manutenção das próprias atividades. Entretanto, os principais motivos percebidos foram a arrecadação de renda ou a distribuição de alimentos - o aumento da fome exigiu organização e coletividade para suprir as necessidades mais básicas das populações, principalmente periféricas. Esses coletivos distribuíram cestas básicas, refeições prontas e até mesmo absorventes, trazendo a questão da "pobreza menstrual", como o grupo "Flores de Resistência".

\subsection{Acesso à informação}

$\mathrm{Na}$ maioria das iniciativas observadas, nota-se uma preocupação com a divulgação de informações sobre a pandemia, reiterando a necessidade de que as pessoas mantivessem os protocolos de segurança sanitária, informando sobre o processo de vacinação e outros cuidados com a saúde. Alguns perfis, como os perfis "bhsemcovid19"18 e "professores na pandemia"19, organizaram-se a partir de boletins diários ou semanais de divulgação da situação da pandemia, do número de mortos e do de infectados, dos dados da vacinação, da defesa do distanciamento social ou mesmo do Sistema Único de Saúde (SUS) e da ciência. Essas campanhas foram fundamentais, diante do negacionismo e da falta de confiabilidade nas informações propagadas pelo governo, pelas fake news e pelas orientações maquiadas de conhecimento científico, como aponta Ana Morel (2021). Parte das organizações também se empenharam em promover denúncias como o racismo estrutural, os assassinatos da juventude negra, o genocídio da população indígena, os ataques contra pessoas em situação de rua e as violências contra mulheres e LGBTQIA+. Isso demonstra que, além de possibilitar o acesso ao conhecimento coletivamente produzido, esses perfis foram espaços de indignação, solidariedade e resistência.

Além disso, a promoção de cursos, oficinas, palestras, cartilhas, cartazes, tanto em modalidade online quanto presencial, nas comunidades, evidencia que existem processos educativos planejados e organizados com o objetivo de compartilhar e produzir saberes por meio das trocas ocorridas. Isso pode ser confirmado, por exemplo, com a cartilha sobre saúde feminina

\footnotetext{
${ }^{17}$ Prestação de contas do coletivo "Serrão Sem Corona". Disponível em: https://evoe.cc/serraosemcorona. Acesso em: 03 de jun. 2021.

${ }^{18}$ Perfil @bhsemcovid19. Disponível em: https://www.instagram.com/bhsemcovid19/. Acesso em: 03 de jun. 2021.

${ }^{19}$ Perfil @ professoresnapandemia. Disponível em: https://www.instagram.com/stories/highlights/18132127735180173/. Acesso em: 03 de jun. 2021.
} 
e pobreza menstrual distribuída pela campanha "\#BHficaemcasa" 20 , os cartazes do coletivo "Teresa de Benguela" para orientação dos direitos das trabalhadoras e legislação ${ }^{21}$, e os cartazes do projeto "Periferia Viva"22 que orientaram os moradores sobre como eles poderiam se proteger do Coronavírus. Essas ações apontam, sobremaneira, para a tentativa de acesso ao emprego, à cidadania, aos direitos e ao autoconhecimento, além da necessidade de se repensar a produção de lixo e a relação da humanidade com o meio ambiente, o que ficou evidente na associação do coletivo "Flores de Resistência"23 com empresas de absorventes, roupas de bebês sustentáveis e fraldas reutilizáveis.

\subsection{Parcerias}

A articulação entre as diferentes iniciativas demonstra como essas parcerias podem ser potencializadoras. Apesar de alguns grupos citados não possuírem uma rede grande de seguidores, foi/é por meio de colaborações que eles conseguiram promover intervenções significativas. Essas intervenções, por sua vez, ocorreram tanto na divulgação mútua das campanhas quanto na ação conjunta para arrecadação de alimentos, promoção de atividades culturais, divulgação de trabalhadores liberais, apoio a pequenos comerciantes e a produtores locais.

Além de empresas, ONGs, associações, artistas, jovens universitários, participantes de sindicatos, de partidos políticos e figuras públicas estiveram na cooperação para o avanço dessas campanhas. Notabiliza-se a atuação, até mesmo, da imprensa e dos jornais televisivos, já que muitos desses grupos foram entrevistados em reportagens.

Ademais, principalmente em relação às atividades artísticas e culturais, a Lei de Incentivo à Cultura $^{24}$ contribuiu para o desenvolvimento de alguns projetos. Salienta-se que a possibilidade do uso desse recurso é proveniente de muita resistência, principalmente dos artistas marginais, que muitas vezes não são selecionados. Por isso, como afirma Camila Cabello (2021), "A Lei Aldir Blanc foi um alento, construído pela sociedade, para minimizar os impactos da pandemia entre os trabalhadores do setor" (s.p.). Dessa forma, esse auxílio financeiro possibilitou que esse setor tão afetado pelo isolamento social pudesse ter alternativas.

\footnotetext{
${ }^{20}$ Disponível em: https://www.instagram.com/p/CDM8Eg8pXNf/. Acesso em 03 de jul. 2021.

${ }^{21}$ Disponível em: https://www.instagram.com/p/CDZ5zOVldkg/. Acesso em 04 de jul. 2021.

${ }^{22}$ Disponível em: https://www.instagram.com/p/CJXFvNRqyfL/. Acesso em 04 de jul. 2021.

${ }^{23}$ Disponível em: https://www.instagram.com/p/CL7UesMJ9X5/. Acesso em 03 de jul. 2021.

${ }^{24}$ Lei de Incentivo à Cultura, disponível em: <http://leideincentivoacultura.cultura.gov.br/>. Acesso em: 04 de jul. 2021.
} 


\subsection{Território nas redes e nas ruas}

Mediante o levantamento dos coletivos cibernéticos, foi identificada a presença dos coletivos mencionados em Belo Horizonte, Contagem, Ribeirão das Neves, especialmente em territórios periféricos como favelas, ocupações, comunidades indígenas e quilombolas. As próprias lutas por moradia, pela não violência do Estado nesses territórios e pela demarcação de terras indígenas são pautas que aparecem nas campanhas. Foi visível, no perfil do Comitê Mineiro de Apoio à Causa Indígena ${ }^{25}$, que há uma articulação entre os povos originários e os periféricos em defesa da demarcação de terras, do acesso à educação e à saúde. Como afirmam, "Historicamente, esses povos e comunidades sofrem com processos de exclusão, opressão e vulnerabilidade, construindo tecnologias criativas e de resistência para preservarem suas vidas e identidades" (2021, s.p.). Considera-se, então, que esses são espaços em disputa - fisicamente, virtualmente e ideologicamente-, já que essas comunidades são excluídas do espaço em que se encontram, ou de ocupar qualquer espaço, como acontece com a população em situação de rua.

Ademais, o ambiente virtual das redes sociais é um campo disputado. A visibilidade que se pode ter com o patrocinamento das publicações ou com o engajamento possibilitado pelos

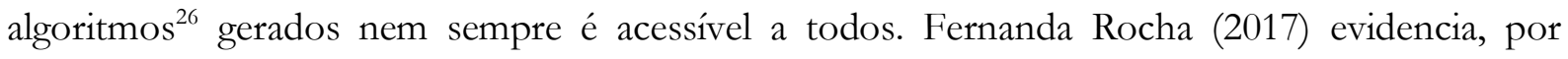
exemplo, como esse é um difícil espaço para mulheres, principalmente por causa do machismo e da exposição. Por isso, impulsionar as campanhas é uma verdadeira luta, que se trava em conjunto.

\subsection{Organização de trabalhadores em busca de emprego}

Alguns grupos, como o "Coletivo Teresa de Benguela", organizaram-se com o objetivo de divulgar trabalhadoras/es autônomas/es em busca de oportunidades de emprego, motivados principalmente pelo aumento do desemprego ${ }^{27}$ e pela diminuição de renda, que geraram insegurança alimentar. Esse grupo, por exemplo, promove capacitação e conhecimento, por meio da orientação dessas trabalhadoras em relação à legislação e aos seus direitos. Elas oferecem os serviços de faxina domiciliar e empresarial, lavanderia e organização de eventos, facilitando o contato entre clientes e trabalhadoras, discutem a questão do racismo no mercado de trabalho e as formas de proteção dessas mulheres. Na pandemia, além da "vaquinha" para contribuir com a renda das profissionais, foi realizada também uma rifa, a fim de manter as ações desenvolvidas.

\footnotetext{
${ }^{25}$ Disponível em: https://www.instagram.com/p/CRPZho6Lxa4/. Acesso em 12 de jul. 2021.

${ }^{26}$ Algoritmo do Instagram é um mecanismo que "decide" o que irá aparecer aos usuários, de acordo com a análise da propensão a determinados assuntos ou perfis.

${ }^{27}$ No primeiro semestre de 2021, após um ano de pandemia, o país tinha 14,8 milhões de pessoas em busca de emprego, segundo dados do Instituto Brasileiro de Geografia e Estatística (IBGE). Disponível em: 〈https://www.ibge.gov.br/explica/desemprego.php〉. Acesso em: 04 de jul. 2021.
} 
Essas iniciativas buscam a valorização de trabalhadoras/res negros/as, nas mais diversas áreas, como saúde, educação ou advocacia, diante da necessidade de fortalecimento desses sujeitos no mercado de trabalho, que ainda é desigual e racista. Há, no mais, uma preocupação com a saúde mental e o autocuidado, tendo em vista as violências vivenciadas.

Portanto, o período de distanciamento social e a pandemia evidenciaram ainda mais a necessidade da organização e da educação de adultos como possibilidade de emancipação, por meio das identidades coletivas, que contribuem para a reflexão e a ação dos oprimidos em prol de sua libertação, como defende Paulo Freire (2002). Além disso, as estratégias utilizadas pelos coletivos demonstram que eles produzem saberes próprios, a partir do momento em que se educam "mediatizados pelo mundo". Assim, esses saberes perpassam pela transição entre "o saber ingênuo" e o "saber crítico", a que Freire se remete, pela ação conjunta em prol da defesa da vida, contra o negacionismo e a necropolítica. Tudo isso, é evidenciado por meio da formação desses sujeitos na defesa de seus direitos e na consciência política e social que adquirem.

Ainda, considerando-se a perspectiva de Carmem Cavaco (2009), a formação experiencial desses adultos, ocorrida por meio dessas vivências, possibilita que, posteriormente, as habilidades adquiridas por eles possam ser utilizadas em benefício do coletivo e de si mesmos. Ademais, esses saberes se constituem históricos e podem promover o avanço da construção de uma sociedade mais justa e equânime, tal como as categorias analisadas reverberam com o levantamento teórico realizado, que aponta para a possibilidade de produção de saberes nas trajetórias coletivas.

\section{Considerações finais}

A necropolítica e o alargamento das desigualdades fizeram com que a organização coletiva e autônoma daqueles que mais foram impactados pela pandemia fosse urgente. A partir disso, desenvolveram-se inúmeras iniciativas na tentativa de contraposição à política de morte. Dessa forma, o período pandêmico impôs para muitos sujeitos a reflexão sobre modos de vida, relação com o corpo, com a comida, saúde, solidariedade e urgência da elaboração de um projeto de transformação social, em contraponto ao agravamento da "crise permanente" a que eles estão sujeitados, como afirma Boaventura Santos (2020).

Além disso, apesar da necessidade de isolamento social, a solidariedade e a construção coletiva exigiram que as pessoas implicadas saíssem de suas casas, com os cuidados possíveis, para lutar pela própria vida e as vidas daqueles que juntamente se organizaram ou seriam atendidos. Nesses caminhos, transpuseram-se fronteiras ideológicas, geográficas e virtuais. Os saberes produzidos, do mesmo modo como aponta Nilma Gomes (2017), contrariam a hegemonia dos 
valores, das crenças e dos modos de vida do Norte do mundo, configurando-se como Epistemologias do Sul, quando esses conhecimentos e os sujeitos neles implicados resistem à dominação neoliberal direcionada aos mercados financeiros.

Salienta-se, por fim, que há diferenças entre os coletivos neste trabalho apresentados, em seus interesses, no alcance que eles têm, ou nas possibilidades educativas que possuem. Por exemplo, a saber, há iniciativas que são para distribuição de alimentos, outras para o fortalecimento de artistas e, ainda, aquelas que buscam, mais do que atender pessoas, caminhar conjuntamente para a divulgação de pautas e confrontar abertamente o sistema. Entretanto, o que neste texto ficou evidente é a potência da organização coletiva que permite que os sujeitos aprendam por meio desses espaços, configurando-se processos educativos na perspectiva da educação de adultos, lembrando que "a educação como prática da liberdade" é um jeito de ensinar que qualquer pessoa pode aprender.

\section{Referências}

BOGDAN, Robert; BIKLEN, Sari. Investigação qualitativa em educaşão: uma introdução à teoria e aos métodos. Portugal: Porto Editora, 1994.

BRASIL. Ministério da mulher, da família e dos direitos humanos. Painel de dados da ONDH. [online]. Disponível em: https://www.gov.br/mdh/pt-br/ondh/paineldedadosdaondh. Acesso em: 7 de jun. de 2021.

BRASIL. Decreto n 10.282, de 20 de março de 2020. Regulamenta a Lei $n^{\circ} 13.979$, de 6 de fevereiro de 2020, para definir os serviços públicos e as atividades essenciais. Brasilia, DF, 2020.

Disponível em: http:/ /www.planalto.gov.br/ccivil_03/_ato2019-

2022/2020/decreto/D10282.htm. Acesso em: 10 de jun. 2021.

HOOKS, bell. Ensinando a transgredir: a educação como prática da liberdade. Trad. Marcelo Brandão Cipolla. São Paulo: Editora WMF Martins Fontes, 2013.

CABELLO, Camila Faustinoni. A emergência da cultura e a Lei Aldir Blanc. Rede Brasil Atual, Blog na rede, 13 de jun. 2021. [online]. Disponível em:

https://www.redebrasilatual.com.br/blogs/blog-na-rede/2021/06/a-emergencia-da-cultura-e-alei-aldir-blanc/. Acesso em: 02 de jul. 2021.

CAVACO, Carmen. Experiência e formação experiencial: a especificidade dos adquiridos experienciais. Revista Educação Unisinos, São Leopoldo, v. 13, n. 3, p. 220- 227, set./dez. 2009.

DAVIS, Angela. Mulheres, Raça e Classe. Tradução de Heci Regina Candiani. São Paulo: Boitempo, 2016.

FREIRE, Paulo. A importância do ato de ler. em três artigos que se completam. 23 ed. São Paulo: Autores Associados: Cortez, 1989. 
FREIRE, Paulo. Pedagogia da autonomia: saberes necessários à prática educativa. São Paulo: Paz e Terra, 1996.

FREIRE, Paulo. Pedagogia do Oprimido. Rio de Janeiro: Editora Paz e Terra, 2002.

GOHN, Maria da Glória. Educação Não Formal, Aprendizagens e Saberes em Processos Participativos. In: Investigar em Educação - Investigar em Educação, II ${ }^{a}$ Série, Número 1, pág.35-50, 2014. Disponível em: http://pages.ie.uminho.pt/inved/index.php/ie/article/view/4. Acesso em: 02 de jul. 2021.

GOMES, Nilma Lino. O Movimento Negro educador: saberes construídos nas lutas por emancipação. Petrópolis: RJ, Vozes, 2017.

NOIS. Núcleo de operações e inteligência em Saúde. Nota técnica 11: Análise socioeconômica da taxa de letalidade da COVID-19 no Brasil. [online]. Disponível em:

https://sites.google.com/view/nois-pucrio/publica\%C3\%A7\%C3\%B5es. Acesso em: 07 de jul. de 2021.

MBEMBE, Archile. Necropolítica: biopoder, soberania, estado de exceção, política de morte. $2^{\mathrm{a}}$ ed. Trad. Renata Santini. São Paulo: n-1 Edições, 2018.

MOREL, Ana Paula Massadar. Negacionismo da Covid-19 e educação popular em saúde: para além da necropolítica. Trabalho, Educação e Saúde [online]. v. 19, 2021. Disponível em: https://doi.org/10.1590/1981-7746-sol00315. Acesso em: 07 de jun. 2021.

ROCHA, Fernanda de Brito Mota. A quarta onda do movimento feminista: o fenômeno do ativismo digital. 2017. 136f. Dissertação (Mestrado Programa de Pós-Graduação em Ciências Sociais ) Universidade do Vale do Rio dos Sinos, São Leopoldo, 2017.

RODRIGUES, Neidson. Educação: da formação humana à construção do sujeito ético. Educaşão e Sociedade, Campinas, v. 22, n. 76, 2001. Disponível em: https://doi.org/10.1590/S010173302001000300013. Acesso em 29 de jun. 2021.

SANTOS, Boaventura de Souza. A cruel pedagogia do vírus. Coimbra: Almedina, 2020. 